\title{
Design and Fabrication of a ruled surface vault with the Exquisite Corpse
}

\author{
Simon Weir ${ }^{1}$ (D) Dylan Wozniak O'Connor ${ }^{1}$. \\ Rodney Watt ${ }^{1}$ - Dagmar Reinhardt ${ }^{1}$. \\ Shayani Fernando ${ }^{1} \cdot$ Jason Dibbs $^{1}$
}

\begin{abstract}
This paper describes the adaptation of the Exquisite Corpse to the design of a vault, cut using only ruled surfaces. The Surrealist process of the Exquisite Corpse, where a group of artists work collectively on a single drawing, without seeing the work of their collaborators, Salvador Dalí called working in "semidarkness". This method succeeds however in producing complex combinations of forms that rarely emerge from solo designers. When a project arose for a vault in a remote environment, the Exquisite Corpse was chosen to generate complimentary and juxtaposing forms from which an architectural language could be later assembled. A model of the vault was fabricated using a robotic arm with a custom built nichrome wire foam cutting end effector from 107 billets of expanded polystyrene. The discussion notes the stereotomic challenges, the differences between the modelled outcome and its stone version, and reflects on maintaining "semidarkness" during early stages of form design.
\end{abstract}

Simon Weir

simon.weir@sydney.edu.au

Dylan Wozniak O'Connor

dylan.wozniak-oconnor@sydney.edu.au

Rodney Watt

rodney.watt@sydney.edu.au

Dagmar Reinhardt

dagmar.reinhardt@sydney.edu.au

Shayani Fernando

shayani.fernando@sydney.edu.au

Jason Dibbs

jason.dibbe@sydney.edu.au

$1 \quad$ Sydney University, Wilkinson Building G04, 148 City Rd, Sydney 2006, Australia 
Keywords Exquisite Corpse - Stereotomy · Vault $\cdot$ Ruled surface $\cdot$ Robotic fabrication

\section{Introduction}

This paper describes an architectural form finding method that deploys and adapts the technique of wire cutting to a problem of architectural expression. The use of stereotomic processes for vault prototypes proceeds from a variation of the work of Fallacara $(2006,2007,2009,2012)$; and the problems of ruled surface stereotomy continues the work on robotic wire cutting by Rippman and Block (2011, McGee et al. (2012), Feringa and Søndergaard (2014), Weir et al. (2016), and Rippmann (2016).

The nominated project was a vault, such that all constituent blocks' faces could be wire cut. The fabrication process for the design model was based on an $A B B$ Multi Axis $\mathrm{CNC}$ robotic arm with abrasive diamond wire saw end effector as used by Gosford Quarries for cutting sandstone (Fig. 1). Our analogue was hot wire cutting expanded polystyrene with a KUKA KR60-3 industrial robotic arm configured with a custom built nichrome wire foam cutting end effector of $1100 \mathrm{~mm}$ length (Fig. 2). In addition, a DKP400 rotating positioner was equipped with a vacuum based gripping table to hold the foam billets in place.

The design constraints were given to a Sydney University design team for a 2 month project. Each participant worked in collaboration with an experienced mason, Charlie Sarkis from Gosford Quarries. While designers worked in relative isolation on their own ruled surface projects, they would also contribute to a collective model. The draft model was collaged from each designer's work, eleven

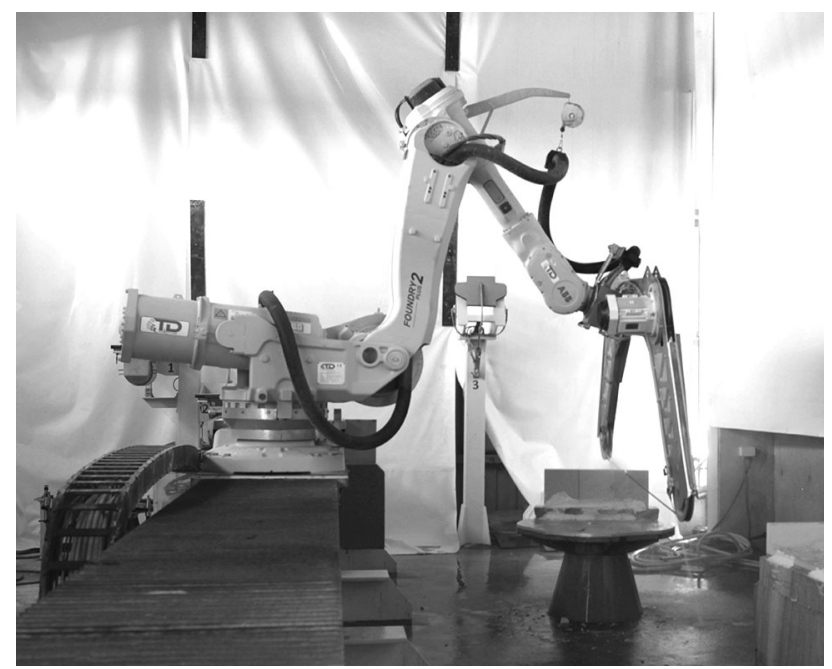

Fig. 1 Gosford Quarries Multi Axis CNC Robot with abrasive diamond wire saw end effector cutting sandstone 


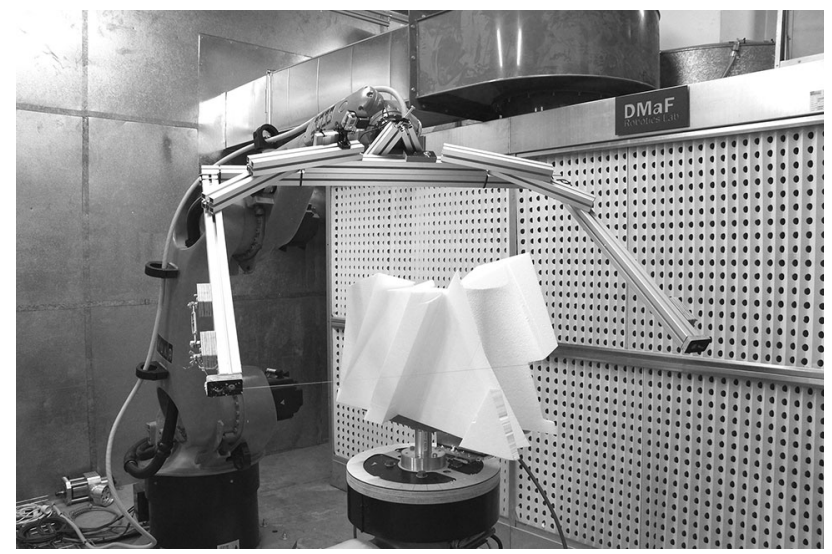

Fig. 2 Sydney University, School of Architecture, Design and Planning, DMaF Lab, KUKA KR60-3 with hot wire end effector cutting foam in an extraction booth

separate parts of the vault assembled into a single object (Fig. 7). This model was cut from 107 billets of expanded polystyrene at a scale of 1:5, producing a model of the vault approximately $3 \mathrm{~m}$ tall (Figs. 10, 11).

First the theoretical background of the Exquisite Corpse process will be explained, with reference to Salvador Dalí's writings about the Surrealist object and architecture. Then the project background will be outlined, accounting for many design constraints and the choice of the Exquisite Corpse and the contemporary reconsideration of the architectural object. With the aims and background in place, the fabrication process is described, concluding with observations on the design process, the limitations of the Exquisite Corpse within the aims of stereotomic architecture, and the formal and procedural differences between the foam model and the final sandstone version.

\section{Exquisite Corpse's Theoretical Background}

The design process was an adaptation of the Surrealist game, Exquisite Corpse, to the form of a vault. The Exquisite Corpse leads a group of artists through the steps of collaboratively producing something. Kochhar-Lindgren et al., in Exquisite Corpse: Chance and Collaboration in Surrealism's Parlor Game explain that although the "rules of the Exquisite Corpse never veer toward an ossification of dogma," a "baseline definition" is best given as an example (Kochhar-Lindgren et al. 2009: xxiii). Imagine the following scenario. Four artists want to make an artwork together. Using some pencils and a sheet of paper, they decide to draw the image of a single standing figure. The sheet is divided horizontally into equal quarters, and each artist assigned one quarter. The first artist draws a head and shoulders on the top quarter of the sheet, then carefully folds it back, concealing their work so that only the bottom edge of their drawing is revealed. The second artist sees this bottom edge and adds the upper torso, and so on, until the final artist 
draws the shins and feet. The completed drawing is a singular person with multiple creators. Not all versions are as formally pre-determined as a person, an Exquisite Corpse landscape by Valentine Hugo, André Breton, Tristan Tzara, and Greta Knutson is now in MoMA (Fig. 3). Though the Exquisite Corpse, given its loose definition, has been adapted to many media, this is the first known use for vaulted architecture (Kochhar-Lindgren et al. 2009: ix).

An emergent criteria for the evaluation of Exquisite Corpse images, that applies to all visual art, is compositional unity. The final drawing can be read as the work of four individual artists, each with their own technique and idiosyncrasies. Yet when viewed and interpreted as a singularly composed image, and in the case of a drawn person the viewer imagines the character of the depicted person, the artists have succeeded in making an image that prompts their audiences imagination with associations that only exist in the viewer's mind. Salvador Dalí's essay "The Object as Revealed in Surrealist Experiment" described the inevitable interpretation of the Exquisite Corpse "as a disturbing and arbitrary 'being' and was credited with having an existence entirely dependent of the experimenter's activity" (Dalí 1932b: 197).

Unlike most forms of visual art, it is not the artists' ideas communicated through a visual language. Although this is not true at the level of each artist's details, it is partly true whenever the boundaries between different artist's sections are misapprehended and multiple artists are percieved as one. It is also true of the composition as a whole, which is a dominant aspect of how an image appears from a distance, or when a viewer misapprehends the image by being unaware of its collaborative origin. The Surrealist character of the Exquisite Corpse is that it invites the audience into confusion. There is a firmly established cultural habit of presuming an exhibited drawing has a single author. The assumption so

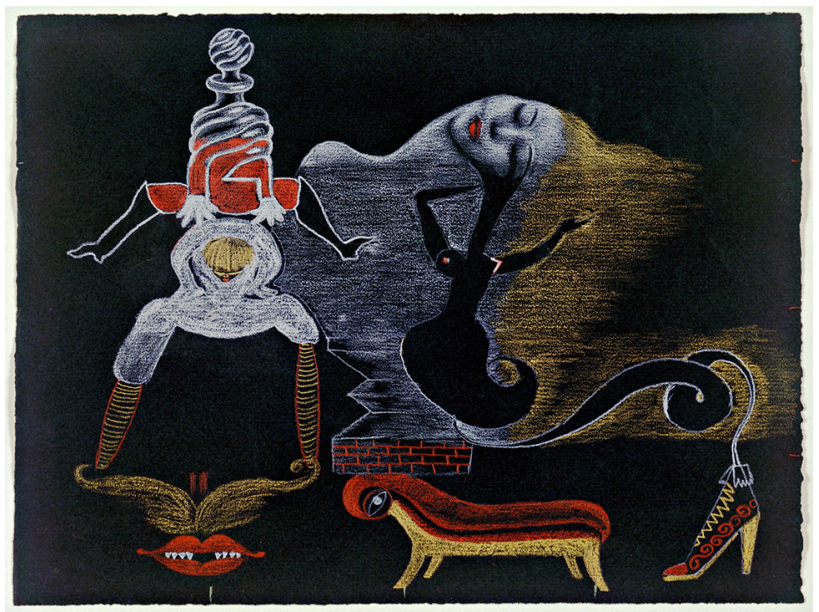

Fig. 3 Breton, Andre; Tzara, Tristan; Hugo, Valentine and Knutsen, Greta (20th cent.): 'Cadavre exquis': Landscape, c. 1933. New York, Museum of Modern Art (MoMA). Composite drawing: colored chalk on black paper, $91 / 2 \times 121 / 2^{\prime}(24.1 \times 31.7 \mathrm{~cm})$. Purchase. Acc. n.:281.1937.C 2018. Digital image, The Museum of Modern Art, New York/Scala, Florence 
predictable that the Exquisite Corpse can be said to deceive its audience on this point. It may be more accurate to describe an Exquisite Corpse as a precise curation of drawings, than $a$ drawing.

The tendency to perceive and misperceive objects from fragments, the Surrealists learned from the principles of Gestalt psychology, especially Hans Prinzhorn's 1922 Artistry of the Mentally Ill. Gestalt psychology described five principles influencing the perception of objects: similarity, continuation, closure, proximity, and figureground relationships. These principles do not engage indiscriminately, but work in the service of six unconscious desires: the urge to play, to interpret, to ornament, to order, to imitate, and the urge for symbolic significance. In perceiving the sculptural forms of columns and vaults, these unconscious urges are inevitably stimulated, "there is a psychological urge whereby 'every shape, no matter now undefined and unobjective, demands interpretation"” (Prinzhorn 1972: 16). In the Exquisite Corpse corpus we always find uneasy and somewhat awkward compositions. In Prinzhorn's terms, compositional unity in an Exquisite Corpse would occur only when the perceiver brings the unity into being through their perception.

Aside from these perceptively unified aspects, the corpus frequently has remarkably beautiful details notable for their distinct juxtapositions. Where these juxtapositions are more subtle, or the juxtaposed areas are somehow more coherent, the effect is of a change in visual complexity; these are the expected outcome of the Exquisite Corpse process that we sought to provoke. In our case the process was going to generate sculptural details, complex formal arrangements and unforeseen aesthetic resonances prompted by juxtaposition.

In Surrealist theory, juxtapositions were one of many strategies for generating forms that are available to accommodate unconscious desires. This radically alienated and alienating aesthetic is a hallmark of the Surrealist vision, expressed aphoristically in Isidore Ducasse's famous line from The Songs of Maldoror, describing someone as beautiful as "the chance meeting on a dissecting-table of a sewing-machine and an umbrella!" (Lautréamont and Lykiard 1970: 177). The aesthetic appeal of juxtapositions occurs partly because they invoke a sense of disorientation, and the contrary affective states that typically accompany it. Anthony Vidler in The Architectural Uncanny documents some of the architectural consequences by separating the safety of home from its secrecy and enforced confinement, from the danger and freedom of homelessness (Vidler 1992). This project however is not operating at the level of program, instead on juxtapositions on the building's skin. Eyelids sprouting hairs adjacent to smooth glistening eyes, thin translucent green leaves attached to hard, brown, hairy, twisting branches: nature is replete with extreme and effortless juxtapositions.

For reasons outlined in the next section, the design needed a formal language separate from known forms generated by functionalism and economic optimisation. Dalí's Surrealist theory of architecture, consistently against functionalism, asserted that in the apparently excessive, in the functionally useless, in the gratuitous gesture, latent desires could find expression. In his 1933 essay, "The Terrifying and Edible Beauty of Art Nouveau Architecture," Dalí wrote that the elements of Art Nouveau buildings that could not be understood as having any apparent purpose would be of use for the "functioning of desires'-desires, moreover, that are the most shady, 
discredited and shameful" (Dalí 1933: 72). In the deviations from expectation, in the anomalies, in the subtle confusions generated by ornamental excess, structural excess, deceptive expression, anything simultaneously endearing and unknown, the unconscious has increased opportunity to indulge in interpretive perception. Wherever the imagination is free to interpolate it glides into projection, and insofar as the contents of the projected imagination can be considered the same as the content of dreams, such architectural details can be said to be oneiric, prompting and accommodating dreams.

The accommodation and provocation of desires were Surrealist aims, especially with regard to Surrealist objects, as Dalí wrote "what matters is the way in which the experiments revealed the desire for the object, the tangible object," (Dali 1932b: 202). The material process of the Exquisite Corpse places the artists in situations where they see the fold and inevitably desire to know what is concealed. Then they "hide the body of work that the next participant might automatically wish for" (Kochhar-Lindgren et al. 2009: xxiii). The concealment stokes a desire that will only be satisfied after everyone has completed their contribution. Due to the immediate physical proximity of the concealed, the original paper and pencil Exquisite Corpse is probably more affectively powerful for the artists than later, blinder variations of the Exquisite Corpse into film or music.

These factors outline both the Exquisite Corpse process, the likelihood of compositional problems, and note that details may be the most engaging elements. Hence this design process can now be understood as a preliminary stage in assembling a formal and aesthetic language for vaults cut with ruled surfaces, an exercise in generating details each of which comprises multiple formal languages. The design will be ultimately comprised of a curation of multiple complimentary and sympathetic groups of forms.

\section{Design Project Background}

"The land grows all of us up... everything that's been and gone and had life in the flesh has died, but the land is still here" (Randall 2006).

One of the most complex issues facing architectural sustainability is the embodied energy of construction materials. This was the core focus for the design of a public building for Indigenous leaders in the heart of Australia's Northern Territory. Isolation produces especially limiting constraints on construction. As a site moves further away from the manufacture of materials and transport terminals, the embodied energy of the building becomes increasingly dominated by transport costs. In the central Australian desert, the nearest sea-ports, steel mills, cement plants, and brick factories are $1800 \mathrm{~km}$ south or $1400 \mathrm{~km}$ north. Any construction based on city techniques would consume half of the project funds on transport.

The site for this project is in Central Australia, just outside the UNESCO World Heritage listed Uluru-Kata Tjuta National Park, a short drive from the small community at Yulara, the resort town that looks south towards the broad sunlit face Uluru, and not far from Mutitjulu, the Indigenous town that looks towards Uluru's shaded southern face, where fresh water was always available, at least until careless 
tourism spoiled that waterhole. Uluru's southern face provides a rare shelter from sun and wind in the flat landscape, providing sanctuary for a tiny, dense ecosystem of flora and fauna. Otherwise, there are very few trees, spaced far apart, and the landscape is covered everywhere with a low dry spinifex grass that grows in round mounds that eventually hollow out, making rings and crescents of green and grey contrasting with the red sand.

Through the year, temperatures move from near $50{ }^{\circ} \mathrm{C}$ during a summer day to near $0{ }^{\circ} \mathrm{C}$ on a winter's night. Most days the sky is a full cloudless blue, the humidity low and the air pure. The hot clear sun touches everything without interruption. After only a few hours of bare sunlight, metals become dangerously hot to touch. By midday metals feel like electrified radiant heaters. By the afternoon, concrete and bricks too feel like radiant heaters, and people casually show you the burns they received from touching their cars earlier in the day.

Even canvas sheets suspended $10 \mathrm{~m}$ off the ground radiate so much heat that their shade is intolerable. The best shelters from the sun are found in the school's playground. Woven through a suspended sheet of light weight cyclone mesh, like chicken-wire, were hundreds of long thin strands of spinifex. Termites eat parts of the spinifex overnight, so it requires regular repair which is adeptly maintained by the school's students. All timber products in this environment quickly lose their strength to termites. Timber could be infused with barrier toxins to terminally discourage these termites, but it is a principle of construction here that we should not introduce pollutants onto the site.

This project was prompted in 2009 by Bob Randall, an elder of the Yankunytjatjara people, who lived in Mutitjulu. He said, "my people see land ownership as being totally different to the English way of ownership. Ours used to be, the lands owns us, and it still is that to us." "When we tried to go to court for land rights, and we came from 'the land owns us', the British system couldn't take that in, they had no way of understanding what we were saying... To come from 'the land owns us', because it's the ancient one, not us. We're the children who come and go. Take what we need for that short time of our lives, and then we pass on to our children who come for another short period. So the human's experience of living is for lots of short periods, but the land stays the same, forever. I think that's where 'the land owns us' is coming from, but when we tried to use that in the first case up Yirrkalla for land rights, we lost, so we had to get used to saying we were the land owners, or traditional owners"(Randall 2006).

Bob Randall's description of the relationship to the land and the short periodic view that each individual human possesses tilts the valuation to the long term. The introductory step of the design challenge here is to select a construction process that produces minimum waste and minimises transport costs. When considering the design problems with Uncle Bob outside his Mutitjulu home, it was discussed that rather than build in light framed steel, wrapped in synthetic insulation, as was common in that area, it would be more comfortable and sustainable to instead produce a purely stone building, cut from the landscape around us; he immediately and easily agreed. The proposal was for a purely public building, a vast covered outdoor space, in some ways a hybrid of the Pantheon and a piazza. The size and shape of a large sand dune, it would provide shelter from the sun, large enough for 
lighting fires in the rain, the roof collecting rain water stored along the northern wall, offering more shade and protection from the seasonal northern storms.

Materially the principle is for an ultra long life building. The sandy environment hosts regular, highly abrasive dust storms, which grind away the object, so the design does not aim for the lean structural efficiency of a building expected to survive decades, but for a thicker, ornamented shell, visibly in excess of the normal expectations. The initial sketch (Fig. 4), small and without detail, drawn onto a site photograph was accepted but the challenge was the means and details. The means consists of importing no construction material, but rearranging the landscape, as Fallacara wrote, inevitably "reinforce the genius of the place" (Fallacara 2009: 554). Pairs of mobile robotic arms will quarry a nearby ridge for billets of dimension stone, hold and cut each piece, and assemble the vault. Diamond wire was chosen based on the estimate that it is lighter to carry to site. The advantages of the construction system includes that broken stone and sand is the only local waste. Also the design and computation can be done remotely, sending cutting information after the size of raw quarried billets are determined.

This stage in the project development is an exploration into the formal languages of design available within the constraints of wire cutting with robotic arms. This problem of architectural language arises here because of symbolic and signification problems. There is no existing local architectural language, and all existing formal languages, Classical, Romanesque, Gothic, Modern, carry cultural associations alien to this environment, and too easily associated with inhospitable forces. Hence the Exquisite Corpse was selected to generate multiple formal systems as potential options for the formal language.

A key criteria for the visual language was complexity, so that the building would appear not as an object in a landscape, but take on a more ambiguous status, with

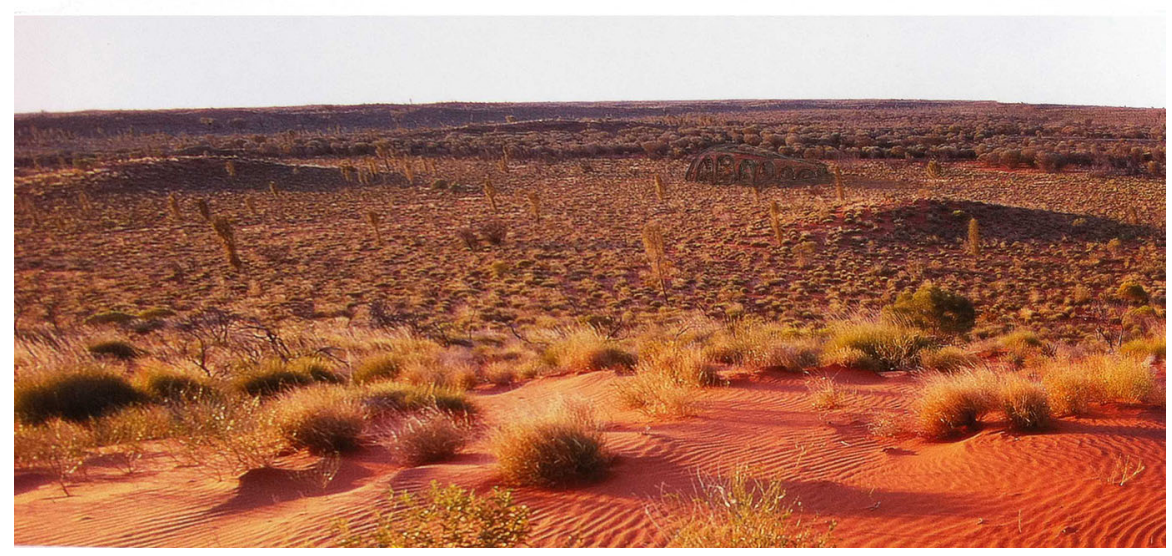

Fig. 4 Concept/sketch design with plan, red and black pen on printed inkjet paper (colour figure online) 
ambitions similar to Mark Foster Gage's Guggenheim Helsinki Design Proposal (Gage 2015: 102-3). The contributions which resulted in the Exquisite Corpse prototype, unifying juxtaposed elements into an autonomous object, and Gage's proposal, respond to the call made by Jason Payne in Log for the "reinvigoration of object study as a disciplinary activity for architecture," especially "the meanings and values of objects" (Payne 2014: 168). Subsequently, it is also exemplary of current trajectories in the ontological discourse; expressly, object-oriented philosophy. One of the major proponents of this discourse, Graham Harman, argues that "objects are sleeping giants holding their forces in reserve" (Harman 2016: 7); it is for this reason that the Exquisite Corpse vault cannot be adequately described by what it is made from nor by what it does. Whilst it is a composite structure, it cannot be readily reduced to its components, and similarly, nor, as an object in perpetual stasis, can it be reduced simply to its actions.

\section{Resulting Vault Design}

The typical Exquisite Corpse begins by nominating the figure and the materials. In this project, we began with a $3 \mathrm{D}$ model of the crescent shaped vault. The base model used thicknesses approximately enough to be structurally stable. The group focused only on two bays of the vault: marked in red in the plan and model (Fig. 5). The model's underlying geometry was traced into Rhinoceros from the hand drawn plan, as a series of arbitrarily drawn intersecting catenary arches, lofted and offset to produce a structure composed a doubly-curved barrel vaults. This form, the maquette-like expression of minimum structure, was further dissected into its basic geometric typologies, which were divided among eleven studio participants: one arch, four half arches, four side vaults and two crowns.

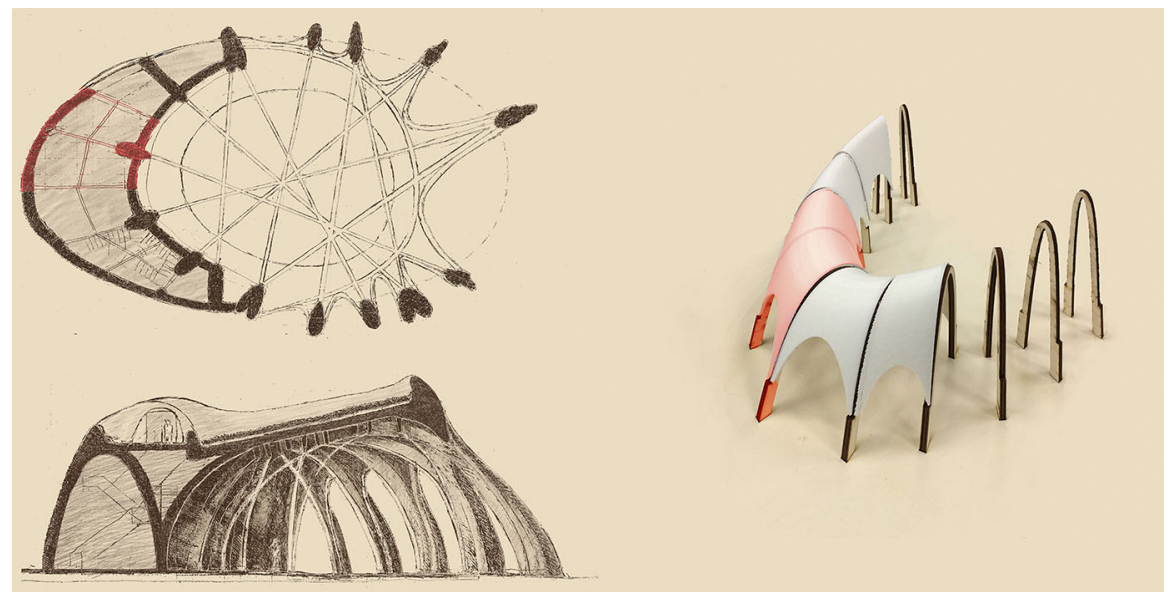

Fig. 5 Left: Concept/sketch plan and section; right: photograph of plywood and PLA diagrammatic detail model, printed from the 3D model given to designers. The part of the building developed in this project's Exquisite Corpse in red (colour figure online) 
Throughout the design process the studio participants undertook two concurrent investigations of the design possibilities of ruled line geometries, the first a formal exploration of the entire structure, the second, a more detailed examination of one of these geometric components. An additional constraint of this second part of the exploration being that no participants would have a component which would perform its structural function without an interaction with a neighbouring vault, arch, or crown; the typological distinction of these forms providing the theoretical fold of the paper concealing the adjacent forms.

The participants' task would be to understand the capabilities and complexities of form and fabrication that wire cutting of sandstone allowed; thickening the minimal provided form into a functional yet exploratory form. Participants modelled, printed and photographed sketch design proposals of both bays (Fig. 6), each adding their own formal variations, including: deceptive appearances (Fig. 6 top right, bottom left); naturalistic modularisation (Fig. 6 lower right); twisting effects with ruled surfaces (Fig. 6 second and third lower from left); and variations on the wave joint (Weir et al. 2016) used for stability (Fig. 7iii, vi). After a long review at this stage with the mason, designs underwent varying changes, from relatively minor scale and joint corrections to full redesign, as their knowledge of the technical requirements of sandstone and wire cutting increased. Next, each the eleven designers' sections were assembled into the Exquisite Corpse model (Figs. 7, 8, 9).

With the digital modelling complete, the fabrication modelling commenced. Each vault, arch, or keystone followed a different design logic, some based off Boolean modelling, some parametric explorations, all subscribing to the underlying requirement for each component to be comprised of ruled-line geometry. For example, the block in red (Figs. 8a, 9a), come from the stereotomic subtractions (Figs. 8c, 9c).

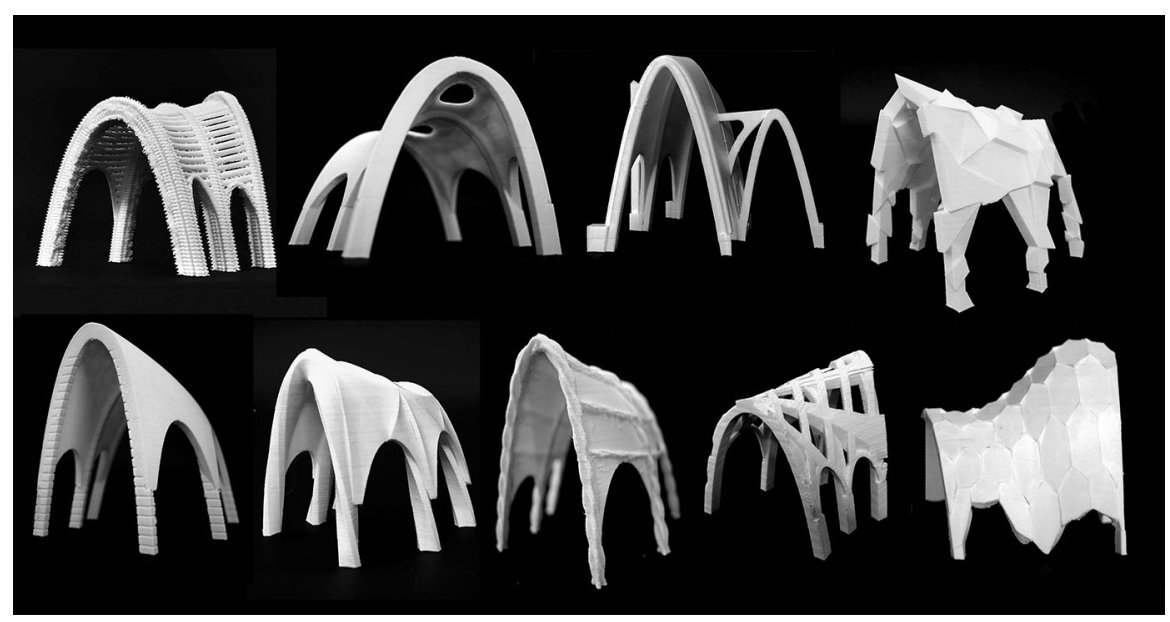

Fig. 6 Photographs of 3D printed vault design models. Left to right, top row: Brennan Clody, Matthew Fuller, Estefano Bonfante, Andrew Wu; bottom row, Sarah Oh, Jerry Feng, Matthew Brooks, Eric Hu, Lewis Miles 


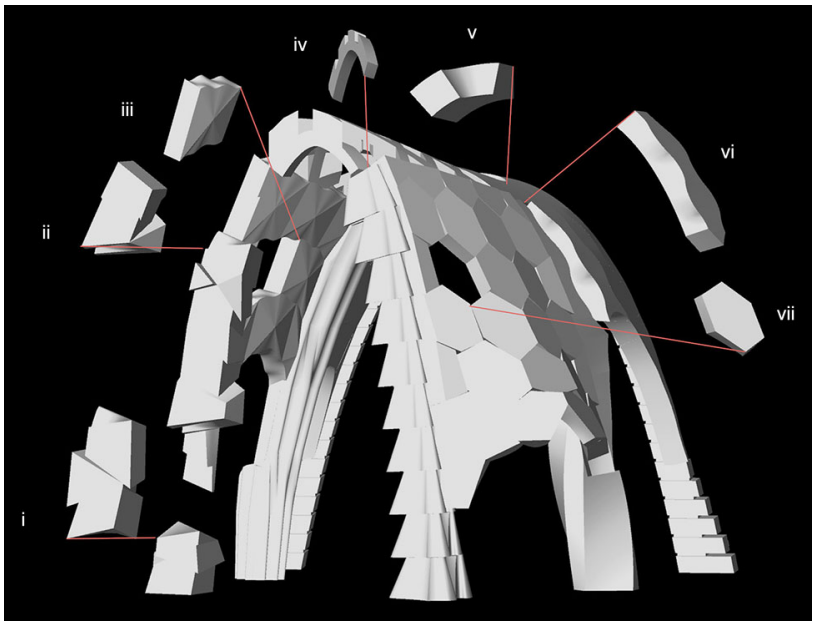

Fig. 7 3D model of Exquisite Corpse vault design with 7 displaced blocks, clockwise from bottom left: i, ii, traditional joint faces concealed by apparently irregular block work; iii, wave joint on horizontal faces to prevent sliding; iv, simple arch as halved-joint; $v$, heavy expression for affect; vi, wave joint extrados with straight joint intrados; vii, hexagonal block
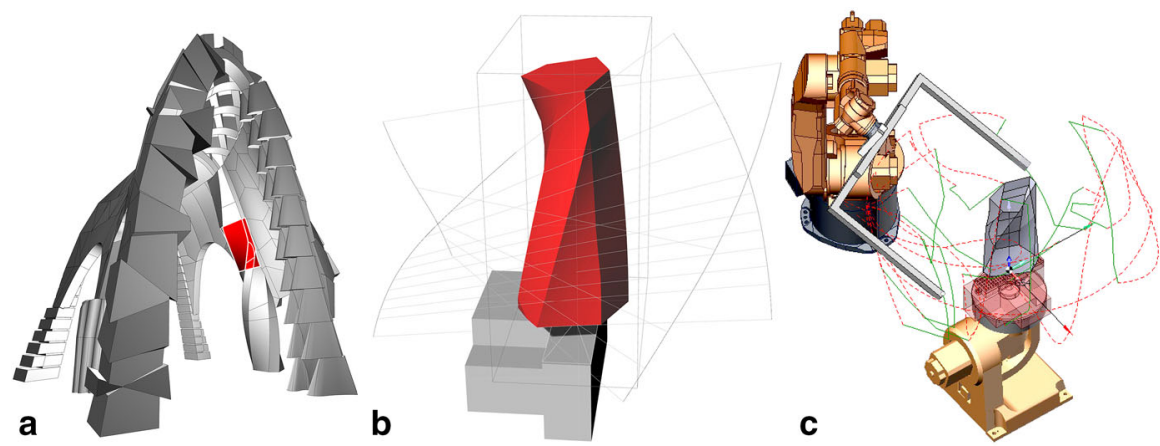

Fig. 8 a Combined model with block identified in red; b block with two stereotomic subtraction paths represented on the design model's in Rhinoceros 3D; c SprutCAM cutting summary: tool paths represented as pairs of lines train each end of end effector vectors paths, the two ends of the wire saw (colour figure online)

The CAM software utilized for fabrication was SprutCAM, configured to generate the necessary KRL code to operate the KUKA robotic arm. Continuous external axis table rotation and toolpath motion were not explored in this particular study, which was constrained to fixed table rotations, however each piece may have utilized up to seven separate rotations depending on complexity, though more commonly only the four orthogonal angles.

Once the designs were processed through SprutCAM, additional control requirements became apparent-in particular, the importance of isocurves and the location of trims on surfaces factored into whether a surface could be processed. These additional considerations were likely due to the way SprutCAM was 


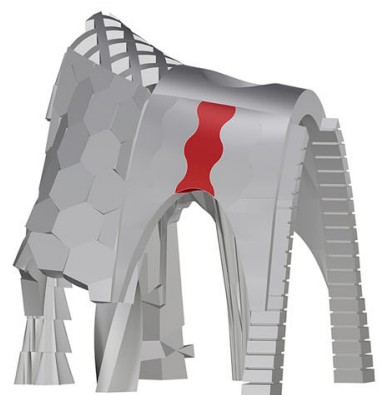

a
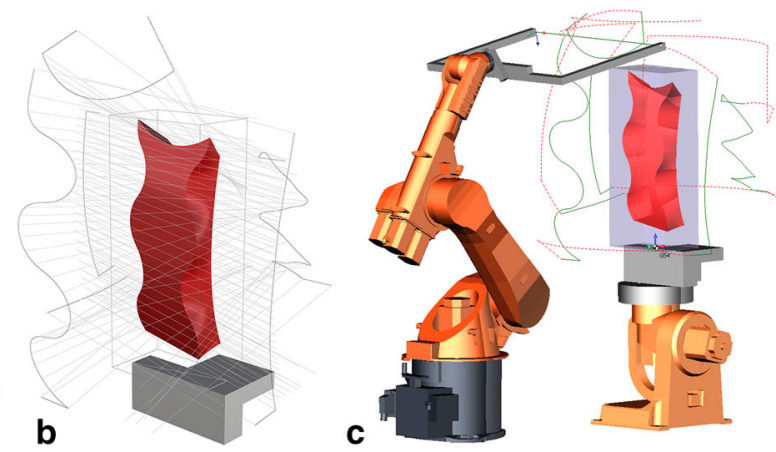

Fig. 9 a Combined model with block identified in red; b block with stereotomic subtraction paths, represented by the heavier line tracing out the movement of one end of sire saw, with the saw blade's angle drawn in thinner lines; $\mathbf{c}$ full set of tool paths (colour figure online)

configured for this project-without native support for wire cutting a workaround was utilized which involved setting the tool centre point at a right angle to the robot roll plate, and utilizing a flank milling process with a tool overhang controlling the point of contact with the wire. The resulting toolpath was hence offset from the controlling surface edge for each cut typically by approximately half the length of the wire (in the region of 300-500 mm). The image taken from SprutCAM show this toolpath and its relation to the finished geometry (Figs. 8c, 9c), the motion follows the extrapolated edge, which may wrap into itself depending on the isocurve spacing and angle.

It was found that in order for a surface to be processed it required many trims to be made along an isocurve, and to have a minimum of four edges, one of which would act as the controlling path, and the perpendicular edges controlling the tilt of the wire throughout the cut. In Rhinoceros $3 D$, this meant some surfaces had to be rebuilt to control the position of the isocurves, or commonly an assisting surface was modelled to control the toolpath with more exactitude.

\section{Limitations of the Exquisite Corpse process within Stereotomic Architecture}

For multiple reasons the principles of stereotomic architecture and surrealist architecture (designed via the Exquisite Corpse) are not yet fully compatible. As Fallacara writes, the notion of stereotomic architecture proceeds logically from its etymological root along a pathway of associations. Ostensibly formed from two Greek words $\left(\sigma \tau \rho o^{\prime}=\right.$ solid and $\tau o \mu \eta '=$ cut $)$, since no Greek example has been found, it is most likely a French neologism. The evidence begins in 16th and 17th century drawings, describing cutting paths for architectural blocks. From this original conception, Fallacara described three principles of stereotomic architecture: the separability of the parts, the ability to precisely describe the parts for subtractive 
fabrication, and that the resulting structure and constituent joints attain "static balance" (Fallacara 2007: 40).

The Exquisite Corpse vault satisfies the principles of separability and description but not structural soundness. Several structural problems were incompletely resolved in the project. The vault was considered in isolation, without the burden of the adjacent structure (right side of the plan/section in Fig. 5). In addition to this change, the lateral forces running along the vault's arched walls were simplified and approximated as balanced. Contributing to this, some of the designs contributing to the whole vault produced increased lateral forces whose forces need to be reiterated back into the design (Figs. 10, 11).

These structural simplifications were compounded by a perception of the two bays of the vault as a whole object rather than a fragment. To illustrate the absent forces, a 1:5 scale structural sketch model of the two-bays was produced with hanging chains, adapted from the higher resolution string model by Tomlow et al. (1989). The model was fabricated with $12 \times 18 \mathrm{~mm}$ galvanised steel chain and $2.5 \mathrm{~mm}$ polypropylene twisted rope, (Fig. 12). The chain loosely approximates the universally distributed load of the shell; the ropes draw out the two catenary arches in each of the side walls. Where these side arches reach the outer arches there is a shift in orientation. This bend is absent in the base model the designers were given, as their base model corresponded to the larger vault, but its absence in the foam model is noticeable, both because the room-sized model is large enough to bear the assumption of completion, and because the mass of the foam itself is not insignificant. This structural misapprehension contributes to the model's uncanny appearance.

Another factor differentiates the Exquisite Corpse vault from pure stereotomic architecture. The formal unity or organicity of stereotomic architecture, linked to the practical utility of maximising repetition and systematising variation, is not the aim of the Exquisite Corpse. The Surrealist aesthetic of juxtaposition corresponds to an architecture with multiple formal systems, and multiple constructive logics. This excess of logic, the excess of complexity, aims to produce a partial unintelligibility, especially in its structurally resolved versions. The only economic advantage to the Exquisite Corpse occurs in the libidinal economy.
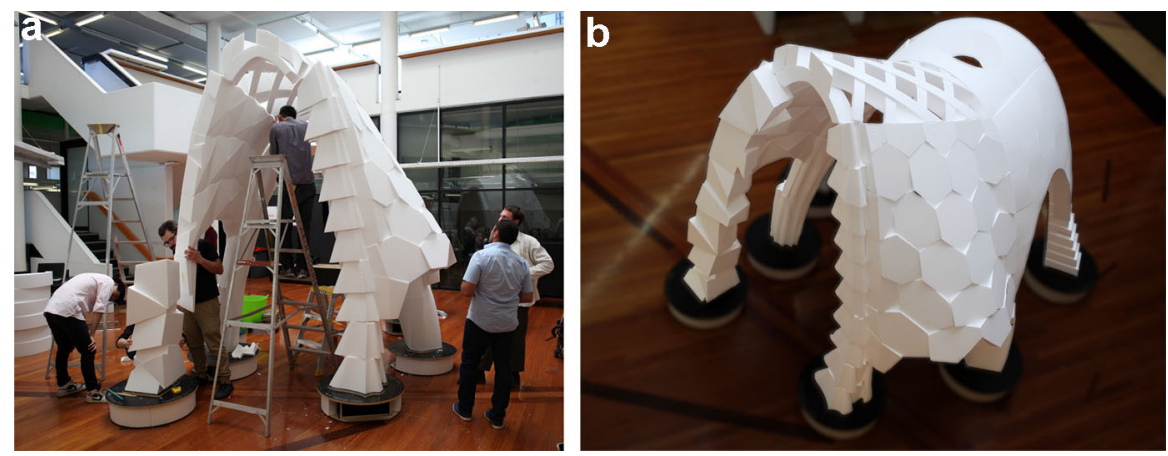

Fig. 10 a Foam model assembly; b foam model, from above 


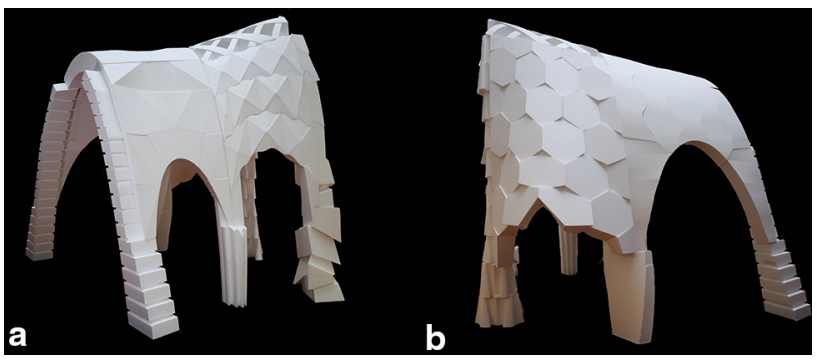

Fig. 11 a Foam model, background removed, inner side; b foam model background removed, outer side

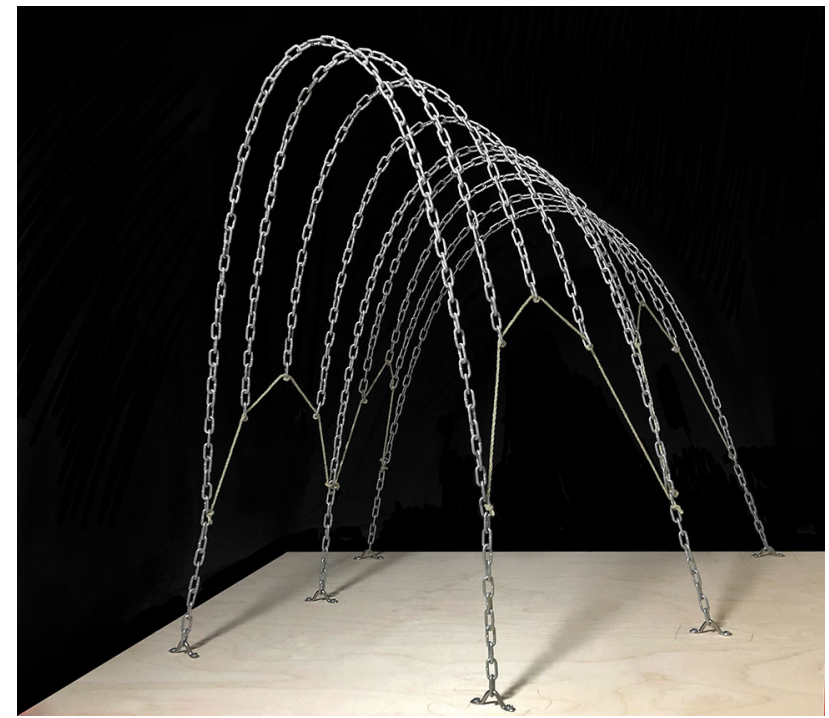

Fig. 12 Inverted photograph of hanging chain model, (1:5 of foam model)

Returning to Dalí's description of the Surrealist aspects of Art Nouveau buildings, we may recall that it was precisely the elements of buildings that could not be understood as having any apparent purpose, the excessive moments of the architecture, that were available for use for the functioning of desires. While these elements were decorative and ornamental in Art Nouveau, in the Exquisite Corpse vault, excess permeates the structure. No individual system is particularly excessive but the whole produces an architecture of overabundance, gratuitousness and monstrously excessive inclusivity. Being an assembly of logics, rather than the expression of one, the vault may be better understood as a landscape or a topography, but the perceptual mechanisms described by Gestalt lead interpretations towards objectification. Hence the vault exists between these perspectives, as a structurally singular Surreal object that insists on its own plurality. Ultimately this project is aiming at assembling a process whereby the architectural Exquisite Corpse will attain all of the stereotomic principles and retain its quality of 

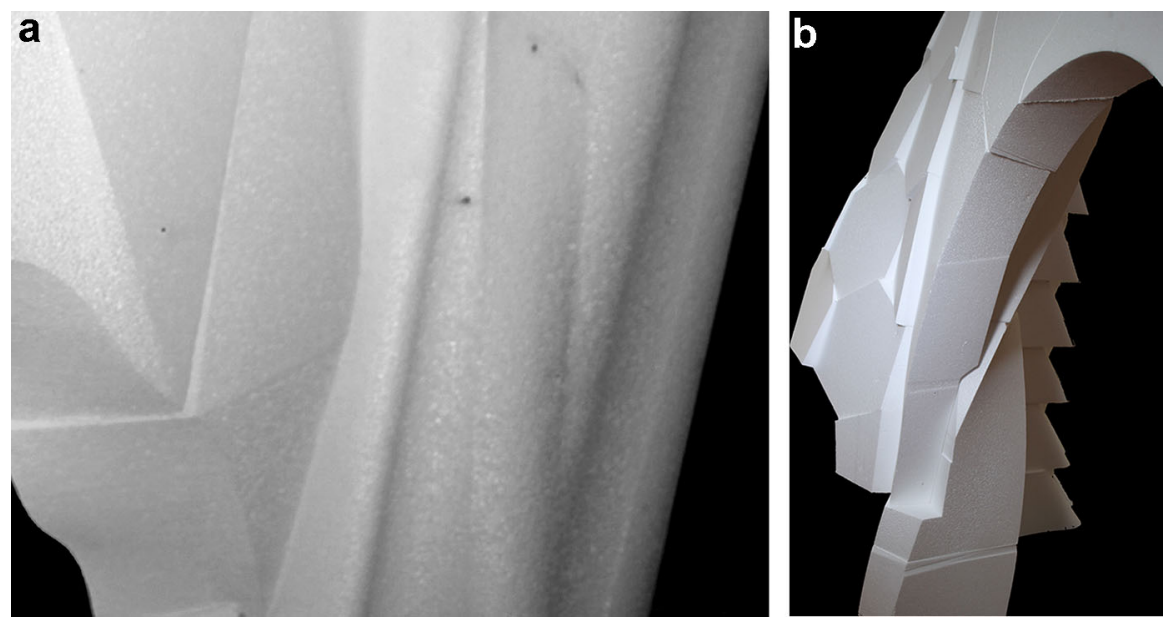

Fig. 13 a Foam model detail with two adjacent designs; b foam model detail with four adjacent designs

monstrous overabundance and libidinal excess. Such an architecture would pose extraordinarily difficult structural problems, but as Dalí wrote about Surrealist images, would also be so "complex, coherent, and involuntary that it escapes the most simple, analysis of logical intuition... [and] materialise... concrete irrationality with the most imperialist fury of precision" (Dalí 1935: 12).

\section{Discussion}

While this fabrication process was intended to study sandstone vaulting, the process did bear differences which should not be overlooked. The speed of fabrication was around $50 \%$ faster than in sandstone as a piece could be machined without the limitations of weight, there were instances where a narrow block was stood on end that may not have been feasible in sandstone. In addition, each toolpath could be executed sequentially without pausing in operation to remove cut elements without fear of breakage or shearing; additional fixings and chocking were not necessary. Some motions such as those that rely on a static rotation about the centre point of the wire, and shallow angle entries of the wire into the material, which were possible in foam, are not feasible when cutting stone with a wire saw. The heated wire could cut the base of a piece without considerations of the crushing weight of the material trapping the wire; the solution to this can be found with a second robotic arm holding the billet which will is yet to be developed.

The Exquisite Corpse process produced the anticipated results, bearing an obvious compositional disorder moderately constrained by the core form, but perceptually it is easily bound together notwithstanding some obvious seams. An aspect of the process of the Exquisite Corpse, is similar to Dalí's paranoiac-critical method, it "is an organizing and productive force of objective chance" (Dalí 1935: 
16) Hence, as anticipated, areas of greater complexity appeared in the chance encounters between multiple designs (Fig. 13); these were the visual highlights of the object. These successful juxtapositions may be replicated as variations to produce architectural elements. As anticipated the joints between arbitrarily cut areas appear to be in need of blending in some instances, and others implausibly successful.

Reflections on the process tend to be aligned with those described in Dalí's essay "The Object as Revealed in Surrealist Experiment". The Exquisite Corpse, Dalí wrote, occurs in "semi-darkness" (Dalí 1932b: 201) a vague term carrying connotations of lighter and darker. In the analogy, darker implies enhancing the degree of systematic de-authoring, increasing the disconnection between individual designers, and between the designer and their work. According to Dalí, this process eventually leads to objects of great metaphysical significance but without craftsmanship (Dalí 1932a). Within the analogy, the intention is to continue lighter: after drawing it out of the darkness with the Exquisite Corpse, there will be a final iterative phase in the full light. The relative darkness of the process was not easy to maintain. During the months fabrication, the whole was slowly revealed: the designer who fabricated their piece first was considerably more blind than the designer who fabricated weeks later. Enforcing too much darkness on the participants disabled the pedagogical process. So the process ran by maintaining confusion about the final object, following Dalí)s strategy, "add a bit of confusion... if things appear too clear" (Dalí 1971: 126). The aim of the confusion on this specific subject is that it produces the affect of unintelligibility inherent and essential to the Exquisite Corpse. The unintelligibility is a mark of provoked desire, which turns designers towards aesthetic details rather than speculating on the whole, and gave designers permission to assert their own formal desires, in preference to negotiating the boundaries.

While these formal explorations have resulted in a prototype in a non-analogous material, the overarching project that this studio germinated from still has many elements which require further resolution, ranging from pure design, through to structural, automation and computational challenges. For instance, there are inherent size and structural limitations with the specific quarried stone which will require design adaptations; the logistical challenge of quarrying and working from the forms which can be gleaned from the context; and the transition to working with sandstone directly will necessitate some variation in approach, restricting and enabling alternate approaches to wire cut geometry. The immediate next stage in this investigation will be to generate a dynamic structural simulation so that each designer's model will register all axial and lateral loads., documenting the necessary modifications to continue compiling the information available to guide further iterations.

Acknowledgements Project team: Simon Weir, Dylan Wozniak O'Connor, Rodney Watt, Dagmar Reinhardt, Shayani Fernando, Lynn Masuda, Jason Dibbs, Charlie Sarkis, Evgeniya Egorova, Hugh Nagle, Matthew Fuller, Sarah Oh, Estefano Bonfante, Lewis Miles, Matthew Gardner, Eric Hu, Matthew Brooks, Jerry Feng, Andrew Wu, Brennan Clody, and with thanks to the anonymous reviewers. 


\section{References}

Dalí, Salvador. 1932a. Psycho-atmospheric-anamorphic Objects. Surrealism at the Service of the Revolution 6, May: 45-48.

Dalí, Salvador. 1932b. The Object as Revealed in Surrealist Experiment. This Quarter (Paris) 5, 1: 197-207.

Dalí, Salvador. 1933. The Terrifying and Edible Beauty of Art Nouveau Architecture. Minotaure, 3-4: 69-76.

Dalí, Salvador. \& Anonymous. 1971. Salvador Dalí goes further with L’Express. L'Express (France), 1-7 March: 126.

Dalí, Salvador. 1935. The Conquest of the Irrational. Paris: Éditions surrealists.

Fallacara, Guiseppe. 2006. Digital stereotomy and topological transformations: reasoning about shape building. In: Proceedings of the Second International Congress on Construction History [Volume 1], 1075-1092. Exeter: Short Run Press.

Fallacara, Guiseppe. 2007. Towards a stereotomic design: Notions of stereotomy, Digital stereotomy and topological transformations: reasoning about the construction of the form. Rome: Aracne Editrice.

Fallacara, Giuseppe. 2009. Toward a Stereotomic Design: Experimental Constructions and Didactic Experiences. In: Proceedings of the Third International Congress on Construction History, Cottbus, May 2009, 553-560. Berlin: Neunplus1. https://structurae.net/literature/conference-proceedings/ proceedings-of-the-third-international-congress-on-construction-history-3-volumes.

Fallacara, Guiseppe. 2012. Stereotomy: Stone Architecture and New Research. Paris: Presses des Ponts.

Feringa, J. and Søndergaard, A. 2014. Fabricating architectural volume: Stereotomic investigations in robotic craft. In: Fabricate: negotiating design \& making, eds. Fabio Gramazio, Matthias Kohler and Silke Langernberg, 76- 83. Zurich: ETH Zurich.

Gage, M.F. 2015. Killing Simplicity: Object-Oriented Philosophy In Architecture. Log 33: 95-106.

Harman, G. 2016. Immaterialism. Malden, Massachusetts: Polity.

Kochhar-Lindgren, K. Schneiderman, D. and Denlinger, T. 2009. The exquisite corpse: Chance and collaboration in surrealism's parlor game. Lincoln: University of Nebraska Press.

Lautréamont, C. d., \& Lykiard, A. 1970. Lautréamont's maldoror (1869). London: Allison \& Busby.

McGee, W., Feringa, J. and Søndergaard, A. 2012. Processes for an Architecture of Volume, Robotic Wire Cutting. In: eds. Sigrid Bell-Cokcan and Johannes Braumann, Robotic Fabrication in Architecture, Art, and Design 2012, 62-71. Vienna: Springer.

Payne, J. 2014. The Strange Case of the Albanian Bunker. Log 31: 161-168.

Prinzhorn, H. 1972. Artistry of the Mentally Ill: A Contribution to the Psychology and Psychopathology of Configuration (1922). New York: Springer-Verlag.

Randall. B. 2006. This Land Owns Us. Global Oneness Project. https://www.globalonenessproject.org/ library/films/land-owns-us. Accessed 15 Oct 2017.

Rippmann, Matthais. 2016. Funicular Shell Design - Geometric approaches to form finding and fabrication of discrete funicular structures, Ph.D. thesis, ETH Zurich. 190-192.

Rippmann, Matthais, and Block, Philippe. 2011. Digital stereotomy: voussoir geometry for freeform masonry-like vaults informed by structural and fabrication constraints. In: Taller, longer, lighter Proceedings of the IABSE-IASS symposium 2011 (London, UK).

Tomlow, J., Graefe, R., Otto, F., Szeemann, H. 1989. Das Modell, The Model. Stuttgart, Germany: Institut für Leichte Flächentragwerke.

Vidler, Anthony. 1992. The Architectural Uncanny. Cambridge MA: MIT Press.

Weir, Simon, and Moult, Dion, and Fernando, Shayani. 2016. Stereotomy of Wave Jointed Blocks: Toward a Wave-Jointed Stone Construction Using Wire Cutter Toolpath Generation. In: eds. Jane Burry, Dagmar Reinhardt, Rob Saunders, Robotic Fabrication in Architecture, Art and Design 2016, 285-293. Cham: Springer.

Simon Weir is Scholarly Teaching Fellow in Architecture at the University of Sydney where he co-leads the Advanced Fabrication Research Studio (2016-2018). His research has both theoretical and technical arms. The theoretical arm connects Salvador Dalí's Surrealist theories of art and Classical theories of the ethics of public architecture. His research on the Classical Greek and Roman architectural custom of "xenia” has been published in RIBA's Journal of Architecture, and Interstices. His Surrealist research has 
been published in the Bauhaus-University at Weimar's journal Horizonte, the journal of the Interior Design Interior Architecture Educator's Association, and Routledge's Interior Architecture Theory Reader. The technical arm is focused on the construction of stone architecture. His research on innovative stone architecture can be found in, RoblArch, CAADRIA, and CAADFutures.

Dylan Wozniak O'Connor is Director of the Design Modelling and Fabrication Lab, Sydney School of Architecture, Design and Planning at the University of Sydney. His work is at the intersection of digital fabrication technology and craftsmanship, applying his knowledge of fabrication and prototyping to develop novel systems and approaches which intermix traditional fabrication, robotics, advanced manufacturing and industry engagement. He has lectured in 3D Modelling and Fabrication and co-leads the Advanced Fabrication Research Studio (2016-2018) - investigating expanded applications of computer numerical control, 3D printing and robotic fabrication technologies. He has worked extensively in the delivery of fabrication based research, on industry engaged and funded experimental applications of industrial robots, as well as contributing to the School of Architecture's Code to Production Research Studios (2015-2018), exploring design robotics and novel approaches to robotic fabrication.

Rodney Watt is a member of the Design Modeling and Fabrication (DMaF) Lab at the Sydney School of Architecture, Design and Planning, Australia. In his current role as Digital Fabrication and Robotics Coordinator, Rodney draws upon a broad range of qualifications and experience including a Master of Engineering from the University of Oxford (Engineering and Materials); a Master of Architecture from the University of Sydney; and past employment in software development in the UK and as the CNC Programmer/Operator at a sandstone company in Australia. He is involved in the design and implementation of construction robotics research processes; training and supervising students, researchers and academics in the programming and operation of industrial robot arms and other digital fabrication equipment; and has coauthored journal articles and book chapters with Dr Simon Weir and Dr Dagmar Reinhardt.

Dagmar Reinhardt is an educator, researcher and director of reinhardt_jung, an architecture practice based in Frankfurt and Sydney that received multiple awards for residential work and has been widely published (https://www.reinhardtjung.de). Reinhardt founded the robotics research group at the School or Architecture, Design and Planning at The University of Sydney, and develops robotic fabrication for architecture applications driven by structural simulation and acoustic performance (2014-18). Reinhardt is a co-editor of Springer Construction Robotics, and regularly publishes in conferences and journals (CAADRIA, RoblArch, CAADFutures). Her industry and government-funded research investigates robotically carbon-fiber woven ceiling structures (2017), and workflow prototyping for human-robot onsite collaboration that solve labour-intensive tasks in construction trades (2018).

Shayani Fernando is a licensed Architect, $\mathrm{PhD}$ candidate and sessional academic with the Sydney School of Architecture, Design and Planning at The University of Sydney. Following graduation she worked in various residential, commercial, educational and non-profit architectural organisations as well as completed an Advanced Architectural degree in Design Technologies at the University of Technology, Sydney. She is recipient of the Young Caadria award, Australasian Center for Italian studies Cassamarca and Swiss Government Excellence Research Scholarships 2017/2018. Her research interests involve stereotomic methods to reform the value of craft; currently working towards the integration of structural design and analysis methods for her thesis The Machine and the Arch: A Stereotomic Exploration of Robotic Crafting for Dry Stone Interlocking Joint Structures.

Jason Dibbs is a PhD candidate and sessional academic with the Sydney School of Architecture, Design and Planning at The University of Sydney. He is a regular contributor to the Danish Architecture Centre's website, https://www.arcspace.com, and his current research is concerned with the intersection of contemporary materialist ontologies with architectural theory and practice. 